\title{
The European Respiratory Society: ensuring excellence through education best practice
}

\author{
Amy Farr ${ }^{1}$, Mina Gaga ${ }^{2}$, Tobias Welte ${ }^{3}$, Thierry Troosters ${ }^{4}$, Guy Joos ${ }^{5}$ \\ Carlos Robalo Cordeiro ${ }^{6}, 0$. Chris Burghuber ${ }^{7}$, Guy Brusselle ${ }^{5}$, \\ Christina-Georgia Gratziou ${ }^{8}$, Andrew Bush ${ }^{9,10}$, Isabel Saraiva ${ }^{11}$, \\ Carine Pannetier ${ }^{1}$ and Daiana Stolz ${ }^{12}$
}

Affiliations: ${ }^{1}$ European Respiratory Society, Lausanne, Switzerland. ${ }^{2} 7$ th Respiratory Medicine Dept, Athens Chest Hospital Sotiria, Athens, Greece. ${ }^{3}$ Pulmonary Medicine, University of Hannover, Hannover, Germany. ${ }^{4}$ Dept of Rehabilitation Sciences, University of Leuven, Leuven, Belgium. ${ }^{5}$ Dept of Respiratory Diseases, Ghent University Hospital, Ghent, Belgium. 'Dept of Pulmonology and Allergy, University Hospital of Coimbra, Coimbra, Portugal. ${ }^{7}$ Otto Wagner Hospital Vienna, Vienna, Austria. ${ }^{8}$ Smoking Cessation Centre, Evgenidio Hospital, Athens, Greece. ${ }^{9}$ Paediatrics Section, National Heart and Lung Institute, London, UK. ${ }^{10}$ Royal Brompton and Harefield NHS Foundation Trust, London, UK. ${ }^{11}$ European Lung Foundation, Sheffield, UK. ${ }^{12}$ Pulmonary Care Division, University Hospital Basel, Basel, Switzerland.

Correspondence: Amy Farr, European Respiratory Society, 4 Avenue Sainte-Luce, CH 1003, Lausanne, Switzerland. E-mail: amy.farrdersnet.org

@ERSpublications

By following education best practices, using available technology to remove barriers and continuing to ensure content remains free from bias, @ERStalk is committed to guiding respiratory health professionals along the path of lifelong learning http://ow.ly/4uUa30leLMb

Cite this article as: Farr A, Gaga M, Welte T, et al. The European Respiratory Society: ensuring excellence through education best practice. Eur Respir J 2018; 52: 1801248 [https://doi.org/10.1183/13993003.012482018].

As we advance through our professional lives, learning is defined not only by earning qualifications and passing examinations, but also by ensuring that we as health professionals have the skills to continue striving in a fast-paced, constantly evolving environment with an increased emphasis on technology, observation and experience. In this digital age, we are inundated with learning opportunities such as textbooks, webinars, massive open online courses, podcasts, conferences, seminars and courses. Learning resources have never been more plentiful or accessible. Every day, we are incited to pursue professional and intellectual development opportunities in ways that are tailored to our individual learning styles and preferences.

Hand in hand with the significant number of learning opportunities comes the significant number of educators and providers of education. Opportunities come from the public sector, hospitals/local institutions, the private sector, nongovernmental organisations, private training institutions and the pharmaceutical/medical device industry, but how does one identify, independent high-quality education? What are the factors that one must consider when choosing educational interventions?

A recent article written by staff and shareholders from the pharmaceutical industry states that industry has a greater part to play in educating health professionals, and calls for accreditation bodies to support their structured framework for the delivery of continuing medical education (CME)/continuing professional development (CPD) [1]. This paper has caused heated discussion, and several rebuttals from international 
accreditation and medical associations [2, 3]. These responses question how educational inventions from one particular industry or company can be free from bias. The rebuttals outline that there needs to be a distinct differentiation made between product training and information, and recommendations for health professionals making important decisions about patient wellbeing in clinical practice.

In this minefield of educational offerings, the European Respiratory Society (ERS) is committed to maintaining its position as an independent source of education, a platform for knowledge sharing and networking, a leader in respiratory research, and a stepping stone for early career professionals looking to take their careers to the next level. As outlined in the ERS 2013-2018 strategic plan [4], education is a key focus area for the society.

Following on from previously published editorials on the subject of education $[5,6]$, this article will introduce the ERS membership, the methodologies used in the development of educational activities, how ERS will strive to ensure accessible and independent content in the future, and importantly, why medical education should be independent and free from bias.

\section{The ERS at a glance}

The ERS is a nonprofit professional membership society with just over 36000 members representing over 160 countries worldwide. The ERS unites all health professionals and scientists working in the field of respiratory medicine with the ultimate aim of alleviating suffering from respiratory disease. The distribution of the professional categories can be seen in table 1. Thus, the ERS has the ambitious task of developing learning interventions for a diverse group of health professionals, all with different health systems, resources, cultures, expectations and local challenges.

The ERS is an organisation developed by respiratory professionals for respiratory professionals. The organisation functions thanks to hundreds of members volunteering to sit on boards, committees, working groups and task forces. These same volunteers spend their weekends, holidays and downtime writing, mentoring, reviewing, assessing and developing activities, all for the advancement of the society and the respiratory field. An important value for the ERS is transparency; as part of our commitment to this, the ERS has joined and additionally established a number of codes of conduct, all of which are publically available on the ERS website [7], that cover topics such as interaction with commercial partners, biomedical research, healthcare professionals and scientific organisations, and the European Medicines Agency.

All members and officers working on ERS activities must complete, at least annually, a declaration outlining all interests and potential conflicts to their activities, which are made available on our website and during presentations. The organisation is supported by nearly 90 staff members employed across three offices in Switzerland, the UK and Belgium.

The ERS was traditionally centred on three main pillars: science, education and advocacy. In recent years, patients and research have also been added as important cross-cutting themes. While this article explores the ERS educational interventions, which normally fall within the purview of the ERS Education Council, these activities could also relate to activities developed within or in conjunction with the other pillars. The ERS has worked to ensure that in the delivery of activities, there is less of a gulf between pillars. It has been established that each pillar needs to interact seamlessly to offer a better service for members and ultimately to ensure that the organisation's mission of better patient outcomes can be achieved.

TABLE 1 Distribution of professional categories among European Respiratory Society members

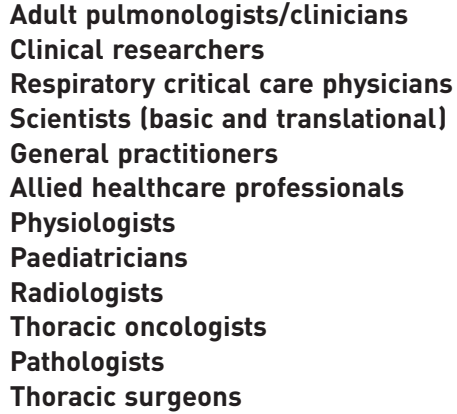

Data are based on a membership survey in which more than one category could be selected. 
ERS has also committed to professionalising respiratory medical education. Over the past 10 years, greater emphasis has been placed on utilising medical education best practices in all activities. Medical education experts from within Europe and throughout the world have been supporting the education leadership to upskill and move from respiratory medicine specialists to respiratory medicine educationalists.

In the following section, we will discuss how ERS develops their programmes and the measures that have been implemented to ensure independence.

\section{Programme development \\ Specialist curricula}

The ERS has designed a number of specialist curricula covering the main disease areas and professional groups (figure 1), which are a basis both for ERS activities, and a guide for national and other international society's activities. These curricula were developed using a structured educational harmonisation framework, an ERS-developed methodology [8], based on a modified Delphi process that involves reaching consensus via a series of questionnaires and focus group discussions.

The ERS methodology, aligned closely to the framework of KeRN et al. [9], involves the following steps. 1) Training needs assessment. 2) Situation analysis. 3) Curriculum development: a) topic selection (syllabus); b) learning outcomes developed (curriculum). 4) Implementation (both through teaching and learning opportunities, and assessment). 5) Evaluation and review.

The ERS now uses this methodology to develop more specialised programmes and currently boasts three structured training programmes on endobronchial ultrasound, spirometry and respiratory sleep medicine [10-12]. A forth structured training programme on thoracic ultrasound is currently under development. The structured, consensus-based approach to developing programmes ensures that they are more balanced and are less influenced by individual beliefs and opinions with regards to a particular topic [13]. Quite often, this approach can lead to some heated and lengthy discussions but this can be seen as only positive, as it challenges the norm and leads to better educational interventions.

\section{Educational interventions}

The ERS runs a number of activities that are open to ERS members and the respiratory community as a whole. As previously mentioned, these activities are developed by ERS members, and supported by the ERS committees and working groups. The educational activities can be classified into: 1) webinars, online courses and case-based learning; 2) symposia, courses, seminars and skills workshops; 3) professional development workshops; 4) educational research (PhD); 5) examinations; 6) clinical observation; 7) simulation learning; 8) mentorship; and 9) fellowships. Each activity is developed by a balanced faculty (in terms of professional background, geographic spread, gender, age, etc.), submitted to peer review and reviewed by an expert board prior to approval of the activity. Where appropriate, the ERS applies

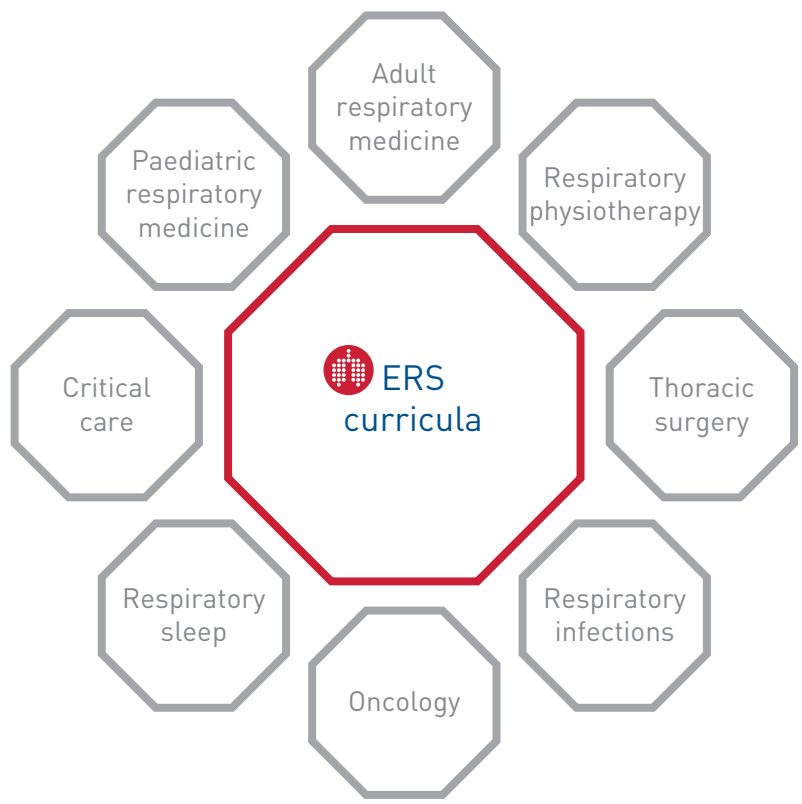


European Board for Accreditation in Pneumology (EBAP) rules and receives accreditation from the EBAP [14] and/or the European Accreditation Council for CME [15].

The policy of the ERS is to lead its own initiatives in support of its mission statement, seeking financial support, in the form of unrestricted grants, where it is deemed necessary and appropriate [16]. Where support from industry is received, the ERS does not accept support from only a single provider. It is worth noting that this ERS policy goes over and above the current accreditation requirements, which currently allow single-sponsor activities.

\section{CPD programme: currently under development}

To complement the existing curricula and to provide a comprehensive educational offering, the ERS has identified an opportunity to create a CPD programme that focuses on a clinician's need to remain "up to date". As recently stated in an article by Stevenson and Moore [17], educational interventions for clinicians often differ from undergraduate and even postgraduate training as the interventions are not based on an explicit curriculum. The most fundamental point about developing a CPD programme for this group is that individuals come from very different backgrounds with different professional experience and therefore, educational interventions cannot be too rigid, and any programme must allow the learner the opportunity to choose their own professional development pathway. Whilst the aim of this project is to identify key topics as a guide, it is not intended as a fully structured and compulsory programme, and it does not look to replace national regulations but to more complement them. Figure 2 outlines the key development focus areas for the programme.

The scientific content will be developed around eight major diseases areas: 1) airway diseases; 2) interstitial lung diseases; 3) paediatric respiratory diseases; 4) pulmonary vascular diseases; 5) respiratory infections; 6) respiratory critical care; 7) sleep and breathing disorders; and 8) thoracic oncology. The first stages of this project will be launched at the 2018 ERS International Congress in Paris, France.

\section{Challenges}

As with any organisation, there are challenges and trade-offs in the development of activities. The ERS is a truly international society, and we are aware of the obligation not only to provide high-quality independent education but also to ensure that the educational activities are affordable to our members and the respiratory community. Attending live events is expensive for a number in our community; whilst bursaries can support some members, the ERS is constantly looking to reduce the barriers to participation. A recent example of how the ERS is looking to mitigate this barrier is by streaming the main lectures from the upcoming thoracic imaging course in October 2018. By paying a small fee, participants will be able to review the lectures, send questions in real time and participate in interactive questions. Social media and other platforms are also currently being explored to implement live events and electronic journal-type interventions. The ERS is committed to using technology to making education more accessible for all.

\section{Future developments}

As well as using technology to break down some of the participation barriers, the ERS is looking at innovative ways to identify needs and knowledge gaps. In addition to providing feedback and input

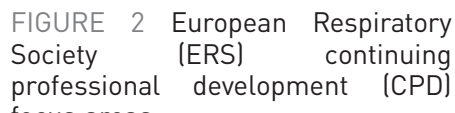

focus areas.

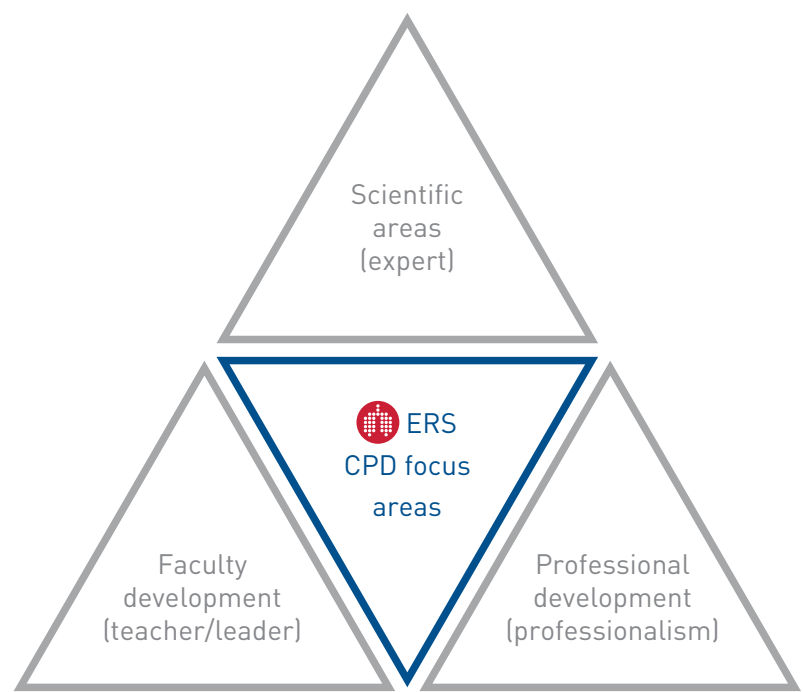




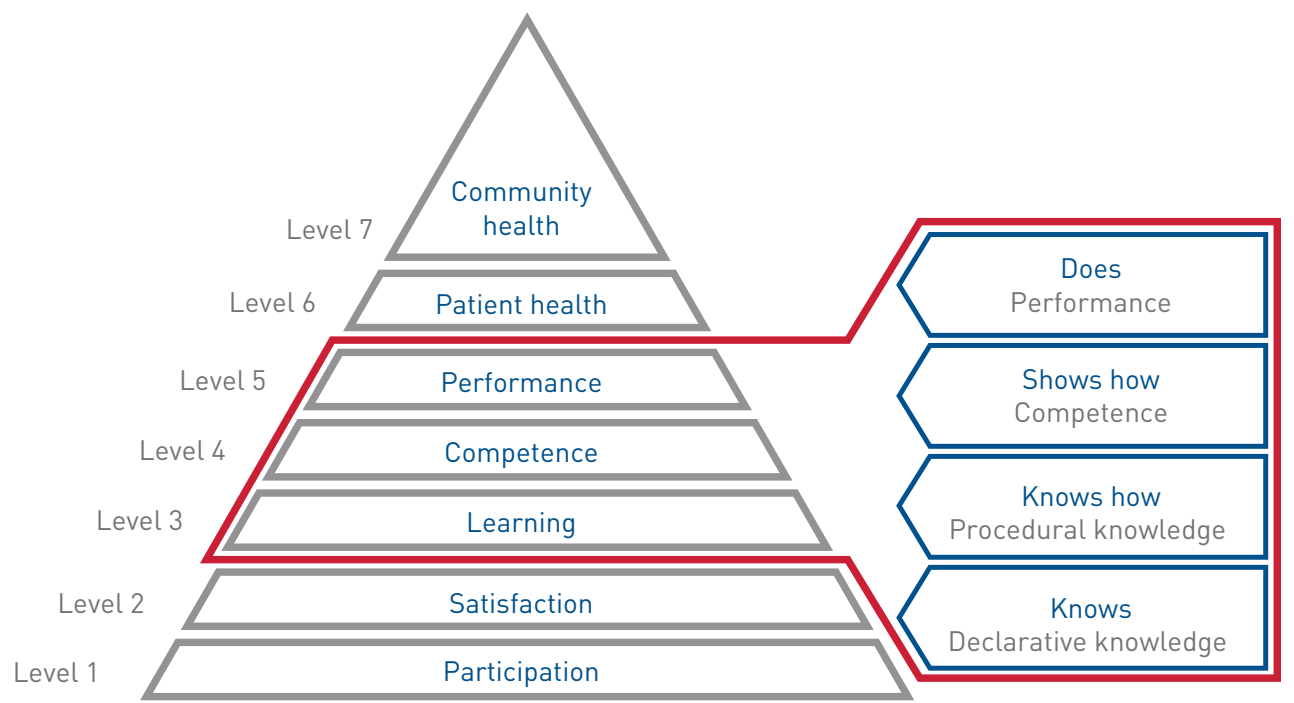

FIGURE 3 Model of continuing medical education outcomes. Reproduced and modified from [18] with permission.

through questionnaires, and reviewing formative and summative assessments linked to individual interventions, at the 2018 International Congress in Paris, delegates will be able to evaluate their level of knowledge through the ERS Game Zone, a self-service, self-assessment area covering both knowledge and basic hands-on skills. This information, along with information from delegates session preferences, will help to tailor the future congress and CPD programme.

The ERS has also committed to systematically measuring the outcomes of these activities in the future. Based on model of CME outcomes of MoorE et al. [18], it can be assumed that current ERS interventions can reach level 4 and potentially level 5 (figure 3); however, better measures need to be implemented to demonstrate this impact across all of our activities.

\section{Conclusion}

By following education best practices, using available technology to remove barriers and continuing to ensure content remains free from bias, the ERS is committed to guiding respiratory health professionals along the path of lifelong learning. However, the challenges to developing, delivering and assessing CME can be only mastered by the joint efforts of professionals, patient representatives, medical societies, regulatory authorities and industry. While medical societies are predestined, entitled and compelled to play the leading role in medical education, it is important that all stakeholders fulfil their specific roles. The ERS is proud to partner with each of them and to continue setting standards for independent, high-quality and innovative education in the respiratory field.

Conflict of interest: A. Farr is an employee of the European Respiratory Society. M. Gaga has nothing to disclose. T. Welte has nothing to disclose. T. Troosters reports that his institution has received speakers fees from Boehringer-Ingelheim and Astra-Zeneca, outside the submitted work. G. Joos reports receiving grants, and personal fees for serving on an advisory board and lecturing from AstraZeneca and Novartis; grants from Boehringer Ingelheim and Chiesi; grants and personal fees for serving on an advisory board from GlaxoSmithKline; and lecture fees from Teva; outside the submitted work. C. Robalo Cordeiro has nothing to disclose. O.C. Burghuber has nothing to disclose. G. Brusselle has nothing to disclose. C-G. Gratziou has nothing to disclose. A. Bush has nothing to disclose. I. Saraiva is Chair of the European Lung Foundation. C. Pannetier is an employee of the European Respiratory Society. D. Stolz has nothing to disclose.

\section{References}

1 Allen T, Donde N, Hofstädter-Thalmann E, et al. Framework for industry engagement and quality principles for industry-provided medical education in Europe. J Eur CME 2017; 6: 1348876.

2 Griebenow R. Industry - from sponsor to provider? J Eur CME 2017; 6: 1395672.

3 European Society of Cardiology Board. The future of continuing medical education: the roles of medical professional societies and the health care industry. Position paper prepared with contributions from the European Society of Cardiology Committees for Advocacy, Education and Industry Relations, Endorsed by the Board of the European Society of Cardiology. Eur Heart J 2018; in press [https://doi.org/10.1093/eurheartj/ehy003].

4 Migliori GB, Rabe KF, Bel E, et al. The European Respiratory Society plans its future: the 2013-2018 strategic plan. Eur Respir J 2014; 43: 927-932. 
5 Palange P, Noel J-LC, Simonds AK. The European Respiratory Society: future directions in medical education. Eur Respir J 2011; 38: 498-499.

6 Mitchell S, Bloch KE, Butiene I, et al. "Education is the passport to the future": enabling today's medical teachers to prepare tomorrow's respiratory health practitioners. Eur Respir J 2014; 44: 578-584.

7 European Respiratory Society. ERS Governance and Transparency. 2018. https://www.ersnet.org/the-society/ who-we-are/ers-governance-and-transparency. Date last accessed: July 17, 2018.

8 European Respiratory Society. ERS curriculum design: a summary of projects. 2018. https://www.ersnet.org/ professional-development/ers-curriculum-design-a-summary-of-projects. Date last accessed: July 17, 2018.

9 Kern DE, Bass EB, Thomas PA, et al. Curriculum development for medical education: a six step approach. Baltimore, JHU Press, 1998.

10 Farr A, Clementsen P, Herth F, et al. Endobronchial ultrasound: launch of an ERS structured training programme. Breathe 2016; 12: 217-220.

11 Mitchell S, Riha RL, Rohde G, et al. Continuing professional development: introducing the ERS International Certificate in Respiratory Sleep Medicine. Breathe 2017; 13: 11-14.

12 Cooper BG, Steenbruggen I, Mitchell S, et al. HERMES Spirometry: the European Spirometry Driving Licence. Breathe 2011; 7: 258-275.

13 Heiko A. Consensus measurement in Delphi studies: review and implications for future quality assurance. Technol Forecasting Soc Change 2012; 79: 1525-1536.

14 European Board for Accreditation in Pneumology. EBAP Accreditation Guidelines. 2018. https://ebap.org/images/ files/EBAP_Guidelines.pdf. Date last accessed: July 24, 2018.

15 European Union of Medical Specialists. EACCME criteria for the accreditation of live educational events (LEE). 2018. https://www.uems.eu/_data/assets/pdf_file/0016/40156/EACCME-2-0-CRITERIA-FOR-THE-ACCREDITATIONOF-LEE-Version-6-07-09-16.pdf. Date last accessed: July 24, 2018.

16 European Respiratory Society. ERS framework for collaboration and interaction with industry partners. 2018. https://ers.box.com/shared/static/6wpmsemx5vt40nbstm115ybmwsonpvuq.docx. Date last accessed: July 17, 2018.

17 Stevenson R, Moore JD. Ascent to the summit of the CME pyramid. JAMA 2018; 319: 543-544.

18 Moore DE Jr, Green JS, Gallis HA. Achieving desired results and improved outcomes: integrating planning and assessment throughout learning activities. J Contin Educ Health Prof 2009; 29: 1-15. 